\title{
STRATEGI ALTERNATIF MEMAJUKAN LEMBAGA PENDIDIKAN ISLAM DI PEDESAAN BERBASIS SEKOLAH EXCELLENT Perspektif Kompetitif Kotemporer
}

\author{
Muhamad Khoirul Umam \\ STAI Badrus Sholeh Purwoasri Kediri \\ khoirul_umam2426@yahhoo.co.id
}

\begin{abstract}
There are changes that occur in our education which impact on regional competitive build towards a global competitive, both in the formal institutions of national and Islamic institutions. So this raises complex issues that wraps acceleration of development in promoting an Islamic educational institutions in rural areas. These problems include institutional, leadership, finance, personnel, curriculum and educational model. Each of these components can inhibit the saving potential and within certain limits can threaten the existence, sustainability, competitiveness, and progress of Islamic educational institutions. The question of research: how is each of these institutions are trying to attract views of rural communities by providing an alternative strategy such as the advantages and characteristics of the institution in the decentralization and globalization?. This research resulted in four alternative bid that is modeling the Islamic educational institutions business model in the financing strategy, improve excellence at regular intervals sustainable in the interests of rural communities, implement the task of public relations in spreading the advancement of excellence of the school, and no achievement or excellence will find both nationally and internationally. Thus meaning that the top schools are part of $a$ plan to be achieved can run well and there are no gaps in it and is able to work by well.
\end{abstract}

Keywords: strategy, business model, excellence, development.

\section{PENDAHULUAN}

Lembaga pendidikan Islam telah banyak muncul dan tersebar dimana-mana termasuk di daerah-daerah yang sangat berat untuk mempertahakan keberlangsungan apalagi kemajuan pendidikan. Sehingga hal ini menimbulkan masalah kompleks yang membelit percepatan perkembangan dalam memajukan suatu lembaga pendidikan Islam di daerah pedesaan. Masalah tersebut meliputi kelembagaan, kepemimpinan, keuangan, kepegawaian, kurikulum, dan model pendidikan. Masing-masing komponen ini menyimpan potensi yang dapat menghambat dan dalam batas-batas tertentu dapat mengacam eksistensi dan kemajuan lembaga pendidikan Islam.

Kultur pedesaan sebagaimana yang dipersepsi dan dipahami oleh kebanyakan orang adalah kurang dalam segi ekonomi, lemahnya kreativitas kultural, belum memahami akan pentingnya kesadaran pendidikan, tetapi memiliki jiwa dan sikap sosial yang kuat. Masyarakat pedesaan memiliki mata pencarian dari pertanian, namun nilai penghargaan ekonomi terhadap hasil pertanian dari tangan petani sendiri amat kecil. 


\section{PROCEEDINGS \\ ANCOMS 2017}

I $^{\text {st }}$ Annual Conference for Muslim Scholars

Kopertais Wilayah IV Surabaya

Kehidupan petani yang hanya berasal dari pertanian sangat sulit berkembang secara dinamis berkelanjutan, dengan kata lain masyarakat pedesaan merasa kesulitan mengembangkan perekonomian hanya dengan pertanian.

Era baru sekarang ini yakni pendidikan di era otonomi daerah banyak diwarnai berbagai kebutuhan juga kepentingan yang bermacam-macam. Dalam menghadapi tantangan besar dan beragam yang harus direspon secara positif dan produktivitas nasional, yakni tantangan dalam peningkatan nilai lebih yang ada pada lembaga pendidikan Islam. Namun keberadaan pendidikan formal yang dinaungi oleh sekolah dan madrasah nampaknya besifat wajib dan harus dipilih dalam katagori pendidikan yang mendasar. Sehingga masing-masing lembaga berusaha menarik pandangan masyarakat pedesaan dengan menyuguhkan strategi alternatif berupa keunggulan dan ciri khas lembaga tersebut.

Selama dua tahun pemerintahan kabinet kerja, Kemendikbud meningkatkan angka Indeks Pembangunan Manusia (IPM) Sebesar 0,75 point dari 68,8 pada tahun 2014 menjadi 69,55 pada tahun 2015 , dengan indeks pendidikan meningkat sebesar 0,82 point dari 60,18 menjadi 6I,00 di tahun 2015. Peningkatan IPM tersebut disebabkan oleh peningkata rata-rata lama sekolah penduduk usia 25 lebih dari 77,3 tahun menjadi 78,3 tahun pada taun 2015 dan peningkatan rata-rata harapan lama sekolah yang meningkat dari 12,39 tahun menjadi I2,55 tahun pada tahun 20I5. Berbagai upaya telah ditempuh untuk meningkatkan akses dan kualitas layanan pendidikan termasuk penguatan peran pendidikan vokasi sebagai langkah strategis peningkatan produktifitas dan daya saing bangsa. ${ }^{1}$

Strategi sebagai bidang yang sangat menarik dalam upaya memenangkan keunggulan bersaing berkelanjutan. Dari sekian lembaga pendidikan Islam di pedesaan, baru beberapa lembaga pendidikan yang berupaya keras menata berbagai komponen pendidikannya sehingga relatif berusaha mampu keluar dari jeratan belenggu masalah yang diuraikan di atas dan berkembang menjadi lembaga pendidikan berbasis excellent dan menjadi alternatif bagi masyarakat.

\section{MAKNA STRATEGI ALTERNATIF}

Pengenalan pengertian strategi perlu disinggung karena merupakan paparan yang menjadi dasar kritis tulisan ini, beberapa pengertian strategi penulis paparkan disini. Strategi sebagai sebuah kata mungkin menjadi lebih dahulu dari istilah manajemen. Strategi sebagai sebuah kosa kata pada mulanya berasal dari kata stratos yang berarti militer dan ag yang artinya memimpin. ${ }^{2}$ Ada pengertian lain yang hampir sama yaitu Strategi berasal dari bahasa latin, "stratos (pasukan) dan "agein" (memimpin). Strategi menjawab pertanyaan mengenai, apa yang ingin kita lakukan, organisasi seperti apa yang kita inginkan, dan kemana organisasi akan menuju. ${ }^{3}$

\footnotetext{
1 Mendikbud Genjot Penguatan Pendidikan Karakter, dalam www.tribunnews.com/30-Desember2016/diakses 9-April-2017.

${ }^{2}$ Purnomo Setiawan dan zulkieflimansyah, Buku Seri Manajemen: Manajemen Strategi, (Jakarta: Penerbitan Fakultas Ekonomi Universitas Indonesia, 2005), 8.

${ }^{3}$ Syaiful Sagala, Manajemen Strategik dalam Peningkatan Mutu Pendidikan (Bandung: Alfabeta, 20I I), I 28.
} 
Strategi adalah arah dan cakupan organisasi yang secara ideal untuk jangka yang lebih panjang, yang menyesuaikan sumber dayanya dengan lingkungan yang berubah, dan secara khusus, dengan pasarnya, dengan pelanggan dan kliennya untuk memenuhi harapan stakeholder. ${ }^{4}$ Jadi ini menimbulkan serangkaian kegiatan memobilisasi sumberdaya lembaga pendidikan untuk meningkatkan kinerja sumberdaya yang ada.

Dalam memahami interaksi kegiatan dalam lembaga pendidikan Islam dimaksudkan tercapainya keunggulan kompetisi yang merupakan serangkaian aktivitas yang dapat mengantarkan lembaga pendidikan Islam berada pada kondisi dimana menguasai dan mempertahankan posisi yang kuat, meredam kekuatan kompetisi dalam lingkungan pendidikan umumnya, membangun dan memanfaatkan sumberdaya lembaga, dan tetap menjaga biaya yang murah dan produk yang spesifik secara berkelanjutan.

Sedangkan strategi alternatif adalah tindakan memobilisasi sumberdaya dalam rangka kompetisi untuk memuaskan pelanggan, mengalahkan pesaing dan mencapai objektifitas organisasi. Dimana objektifitas organisasi merupakan model bisnis cara memperoleh pembiayaan dan seraingkain kegiatan yang tidak bisa lepas dari analisis lingkungan internal dan juga manajemen strategi. Sehingga proses lembaga pendidikan Islam dalam menyusun visi, misi, menentukan objek, merangkum strategi, mengimplementasikan dan mengeksekusi strategi dapat berjalan secara berkelanjutan dan dapat melakukan tindakan perbaikan dalam visi, misi, objek dan strategi lembaga pendidikan Islam tersebut.

Setidaknya ada tiga pengertian strategi. Pertama, strategi merupakan deklarasi maksud yang mendefinisikan cara untuk mencapai tujuan, dan memperhatikan dengan sungguh-sungguh alokasi sumber dan mencocokan sumber daya dan kapabilitas dengan lingkungan ekstenral. Kedua, strategi merupakan perspektif dimana isu kritis atau faktor keberhasilan dapat dibicarakan, serta keputusan strategis bertujuan untuk membuat dampak yang besar serta jangka panjang. Ketiga, strategi pada dasarnya adalah mengenai penetapan tujuan dan mengalokasikan atau menyesuaikan sumber daya dengan peluang, sehingga dapat mencapai kesesuaian strategis antara tujuan strategis dan basis sumber daya. ${ }^{5}$

\section{MENYADARKAN MASYARAKAT PEDESAAN TERHADAP PEMBIAYAAN PENDIDIKAN}

Kondisi sekolah pedesaan sebagaimana dipaparkan di pendahuluan, khususnya sekolah yang berada di pedesaan sungguh sangat memperhatikan. Sekolah terhimpit oleh berbagai kesulitan yang menyangkut sumber daya mausia (SDM), sarana prasaana, kepercayaan masyarakat, perlakuan soisal, jaringan keluar, krisis keuangan, dan sebagainya. Belakangan ini mungkin agak melegakan karena ada bantuan operasional sekolah (BOS) sehingga beban-beban yang dipikul sekolah agak terkurangi. Kepedulian dari pemerintah ini dapat dimaanfaatkan untuk meringankan derita sekolah. Haya saja

\footnotetext{
${ }^{4}$ Triton, Manajemen strategis Terapan Perusahaan dan Bisnis (Jakarta: Oryza, 20I I), I5.

${ }^{5}$ Michael Amstrong, The Art of HRD, Strategic Human Resource Management a Guide in Action Manajemen Sumber Daya Manusia Strategik Panduan Praktis untuk Bertindak, alih bahasa oleh Ati Cahyani, (Jakarta: PT Gramedia, 2003), 39-42.
} 
masih banyak kebutuhan lain yang belum dapat diatasi sekolah kendati sekolah sudah mendapatkan dana bantuan tersebut.

Bantuan Operasional Sekolah (BOS) adalah progam pemerintah yang pada dasarnya untuk penyediaan pendanaan biaya operasi nonpersonalia bagi sekolah dasar sebagai pelaksana progam wajib belajar. ${ }^{6}$ Biaya nonopersonalia adalah biaya untuk bahan atau peralatan pendidikan habis pakai, dan biaya tak langsung berupa daya, air, jasa telekomunikasi, pemeliharaan saran prasarana, uang lembur, transportasi, konsumsi, pajak, dan juga beberapa jenis pembiayaan investasi dan personalia yang diperbolehkan dibiayai dengan dana BOS. ${ }^{7}$

Dana BOS diketahui oleh masyarakat. Mereka mempersepsi bantuan ini secara berlebihan. Ketika masa penerimaan siswa baru, di kalangan pedesaaan, mereka baru mau memasukkan putra-putrinya ke sekolah gratis dan uang beberapa ribu rupiah. Akibat, adanya dana BOS hanya membuat masyarakat menuntut sekolah menyebar seragam sekolah dan uang gratis. Mereka mengira bahwa bantuan itu jumlahnya berlebihan sehingga seharunya didistribusikan kepada calon-calon siswa baru. Padahal penggunaan dana BOS hanya digunakan untuk membiayai kegiatan-kegiata sebagai berikut: I) Pembelian buku teks pelajaran untuk dikoleksi di perpustakaan; 2) Pembiayaan seluruh kegiatan dalam rangka penerimaan siswa baru dan pendaftaran ulang siswa lama; 3) Pembiayaan kegiatan pembelajaran remedial, pembelajaran pengayaan, pemantapan persiapan ujian, olahraga, kesenian, karya ilmiah, pramuka, dan palang merah; 4) Pembiyaan ulangan harian, ulangan umum, ujian sekolah, dan laporan hasil belajar; 5) Pembelian bahan-bahan habis pakai; 6) Pembiyaan langganan daya dan jasa; 7) Pembiayaan perawata sekolah; 8) Pembayaran honorium guru dan tenaga kependidikan; 9) Pengembangan profesi guru; 10) Pemberian bantuan transportasi bagi siswa kurang mampu; II) Pembiayaan pengelolaan biaya BOS; I2) Pembelian komputer dan printer untuk kegiatan siswa. ${ }^{8}$

Peran manajer harus mampu memunculkan strategi alternatif yang terus menerus menata dan meningkatkan kualitas sekolahnya secara bertahap agar mendapatkan kepercayaan masyarakat termasuk sebagai lembaga pendidikan Islam yang dipilih mereka bagi kepentingan pendidikan putra-putrinya. Semakin banyak perbaikan dan keunggulan sekolah, maka akan semakin meningkatkan posisi tawarannya di masyarakat, termasuk dalam persoalan penerimaan siswa baru. Sekolah yang memiliki berbagai keunggulan akan menumbuhkan kepercayaan masyarakat. Kepercayaan ini bukan takdir melainkan dapat dirintis dan dibangun utnuk mewujudkan sekolah unggulan di pedesaan.

\section{MENGEMBANGKAN KULTUR GEOAGRAFIS LEMBAGA PENDIDIKAN ISLAM}

Dari peta geografis keberadaan lembaga pendidikan Islam, timbulnya pertanyaan mungkinkah lembaga pendidikan Islam dimajukan di desa? Tidak ada istilah tidak mungkin dalam persoalan memajukan lembaga pendidikan Islam. Parameter kemajuan

\footnotetext{
${ }^{6}$ Peraturan Menteri Pendidikan dan Kebudayaan Nomor 16 tahun 2016.

${ }^{7}$ Peraturan Pemerintah Nomor 48 Tahun 2008.

${ }^{8}$ Mujamil Qomar, Strategi Pendidikan Islam (Jakarta: Erlangga, 2013), 298-299.
} 
lembaga pendidikan Islam yang tersebar di pedesaan adalah jangkauan kemajuan desa, tetapi dalam kemajuan perkembangannya bisa memakai parameter kemajuan kota. Masih ada celah-celah untuk memajukan sekolah Islam yang berada di pedesaan, antara lain sebagai berikut: I) Membangun dan meningkatkan profesionalisme kepala sekolah Islam; 2) Membangun dan meningkatkan profesionalisme guru; 3) Membangun dan meningkatkan sumber daya manusia semua pegawai; 4) Berusaha secara terus-menerus meningkatkan kesejahteraan seluruh pegawai secara signifikan; 5) Memberi pelayanan prima kepada semua lapisan masyarakat; 6) Berorientasi pada pencapaian kualitas yang berkesinambungan; 7) Berusaha keras dan kontinu membangun citra sehingga sekolah Islam; 8) Gencar melakukan publikasi prestasi-prestasi yang diraih; 9) Berusaha membuat jaringan yang kuat dengan lembaga lain. ${ }^{9}$

Dengan menempuh langkah-langkah tersebut secara konsisten dan konsekuen berkelanjutan, lembaga pendidikan Islam akan mencapai kemajuan, kendatipun lokasinya berada di pedesaan. Jika lembaga pendidikan Islam di pedesaan mampu menunjukan kemajuan yang riil di hadapan masyarakat sehingga mereka dapat menyakini akan potensi lembaga pendidikan Islam itu, anak-anak kota sekalipun akan dikirim untuk mengikuti pendidikan Islam yang berada di pedesaan.

\section{DESENTRALISASI LEMBAGA PENDIDIKAN ISLAM}

Istilah desentralisasi mengandung makna bahwa proses pendelegasian atau pelimpahan kekuasaan atau wewenang dalam sistem organisasi diberikan dari pimpinan atau atasan ke tingkat bawahan. Sementara desentralisasi pendidikan Islam mengandung makna bahwa suatu lembaga yang lebih rendah kedudukannya menerima penyerahan kewenangan untuk melaksanakan segala tugas pendidikan, termasuk pemanfaatan fasilitas yang ada serta penyusunan kebijakan dalam pembiayaan. ${ }^{10}$ Dalam melaksanakan desentralisasi pendidikan ini, terdapat restrukturisasi sistem manajemen pendidikan di Indonesia yang mencakup hal-hal sebagai berikut: I) Struktur organisasi hendaknya terbuka dan dinamis; 2) Saran pendidikan dan fasilitas pembelajaran dibakukan berdasarkan prinsif edukatif; 3) Tenaga kependidikan, terutama tenaga pengajar harus direkrut melalui proses seleksi; 4) Struktur kurikulum pendidikan hendaknya mengacu pada penerapan sistem pembelajaran tuntas; 5) Proses pembelajaran tuntas diterapkan dengan berbagai modus pendekatan pembelajaran; 6) Sistem hasil belajar secara berkelanjutan; 7) Dilaksanakan supervisi dan akreditasi; 8) Pendidikan berbasis masyarakat; 9) Formula pembiayaan pendidikan dan subsidi pendidikan. ${ }^{11}$

Desentralisasi pendidikan Indonesia merupakan peluang baik untuk meningkatkan demokrasi pendidikan, efesiensi manajemen pendidikan, relevansi pendidikan, dan mutu pendidikan. Desentralisasi pendidikan memberikan keleluasan bagi sekolah untuk maju dan berkembang sesuai dengan core value yang dibangun dan dikembangkan untuk menjadi sekolah yang unggul dan diminati masyarakat.

\footnotetext{
${ }^{9}$ Mujamil Qomar, Strategi Pendidikan Islam (Jakarta: Erlangga, 2013), 338-339.

${ }^{10}$ Prim Masrokan Mutahar, Manajemen Mutu Sekolah Strategi Peningkatan Mutu dan Daya Saing Lembaga Pendidikan Islam (Yogyakarta: AR RUZZ Media, 20I4), I I 7.

${ }_{11}$ Musa, Otonomi Penyelenggaraan Pendidikan Dasar dan Menengah. Jurnal Pendidikan vol. 2 NO. 2 September 200I.
} 


\section{PROCEEDINGS}

\section{ANCOMS 2017}

I ${ }^{\text {st }}$ Annual Conference for Muslim Scholars

Kopertais Wilayah IV Surabaya

Sekolah yang unggul dan diminati oleh masyarakat merupakan tantangan yang harus diraih oleh setiap sekolah Islam dalam meningkatkan mutu pendidikan di era desentralisasi pendidikan. Desentralisasi pendidikan yang efektif tidak hanya melibatkan proses pemberian kewenangan dan pendanaan yang lebih besar dari pemerintah pusat ke pemerintah daerah, tetapi juga harus menyentuh pemberian kewenangan yag lebih besar ke sekolah Islam dalam menentukan kebijakan-kebijakan tentang organisasi dan proses belajar mengajar, manajemen, struktur dan perencanaan strategis di tingkat sekolah, dan sumber-sumber pendanaan sekolah. Sekolah Islam harus mampu mengadakan inovasi dan mengambil kebijakan strategis dalam meningkatkan mutu pendidikan yang berlandaskan pada standar minimal pendidikan.

Desentralisasi pendidikan terjadi jika pemerintah pusat menetapkan keputusan yang secara formal telah dibuat di tingkat pusat dapat dibuat di tingkat lebih bawah yang mengurusi masalah pelayanan pendidikan. Desentralisasi pendidikan Islam merupakan bentuk riil dalam memberdayakan satuan pendidikan atau sekolah Islam sebagai unit layanan utama yang mandiri dan memberdayakan dirinya secara cerdas dan optimum. Pemberdayaan sekolah Islam secara mandiri ini sangat penting agar sekolah mampu berkembang secara konstruktif dalam meningkatkan mutu pendidikannya. Untuk meningkatkan mutu pendidikan dalam sistem desentralisasi ini, dibutuhkan kreativitas sekolah Islam untuk mengkreasi mutu lembaga pendidikan yang diinginkannya berdasarkan undang-undang sistem pendidikan nasional dan standar nasioanl pendidikan yang telah ditetapkan oleh pemerintah.

\section{MENGEMBANGKAN PENDIDIKAN ISLAM SEKOLAH EXCELLENT KEKINIIAN}

Keberhasilan sekolah merupakan ukuran yang bersifat mikro yang didasarkan pada tujuan dan sasaran pendidikan pada tingkat sekolah sejalan dengan tujuan pendidikan nasional serta sejauh mana tujuan itu dapat dicapai pada periode tertentu sesuai dengan lamanya pendidikan yang berlangsung di sekolah. Berdasarkan sudut pandang keberhsilan sekolah tersebut, kemudian dikenal sekolah unggulan dan efektif, efesien yang mengacu pada sejauh mana sekolah dapat menacapai tujuan dan sasaran pendidikan yang ditetapkan. ${ }^{12}$ Dengan kata lain, sekolah Islam disebut unggulan jika sekolah tersebut dapat mencapai apa yang telah direncanakan.

Sekolah unggulan adalah sekolah yang mampu meningkatkan penguasaan ilmu dan keterampilan guru agar dapat membantu siswa belajar sebagaimna mestinya. Meningkatkan kemampuan guru, mengembangkan kemandirian siswa belajar, melakukan eksplorasi, elaborasi dan konfirmasi dalam penguasaan informasi, menerapkan pengetahuan dalam berbagai produk belajar yang nyata dan dapat ditunjukkan dalam bentuk lisan, gerak, maupun tulisan. ${ }^{13}$ Ada empat katagori sekolah apabila dilihat dari mutu dan proses pendidikannya, yaitu sekolah yang buruk, sekolah

\footnotetext{
${ }^{12}$ Nur Efendi, Membangun Sekolah Efektif dan Unggulan (Tulungagung: IAIN Tulungagung Press, 20 I4), 7

${ }^{13}$ Syafrudin, Manajemen Lembaga Pendidikan Islam (Jakarta: Ciputat Press, 2005), 160.
} 
yang baik, sekolah yang efektif, dan sekolah yang unggul. ${ }^{14}$ Sedangkan sekolah unggulan adalah sekolah yang inputnya sangat baik, prosesnya sangat baik dan menghasilkan lulusan atau output yang sangat baik sebagai tolak ukur rintisan pengembangan pendidikan Islam sekolah excellent. Lazimnya memang formula input, proses dan ouput ini selau dipakai. ${ }^{15}$

Berpijak dari korelasi tersebut, maka semua lembaga pendidikan Islam pasti berharap memiliki input yang baik, prosesnya baik sehingga outputnya pun pastilah terjamin baik itu yang namakan sekolah unggulan. Sedangkan sekolah unggul dan efektif adalah sekolah yang mampu memiliki dampak pembelajaran untuk mencapai semua misi, menunjukan adanya kesamaan dalam mutu maupun kualitas. ${ }^{16}$

Sekolah unggulan memiliki strategi khusus di bidang manajemen, yaitu upaya untuk mengembangkan sistem manajemen sekolah sehingga secara kelembagaan sekolah akan memiliki kemampuan-kemampuan sebagai berkembangnya prakarsa dan kemampuaankemampuan kreatif dalam pengelolaan pendidikan, tetapi tetap berada dalam bingkai visi, misi serta tujua kelembagaan sekolah, berkembangnya organisasi pendidikan sekolah yang lebih berorientasi pada profesionalisme, dari pada hirarki, dan layanan pendidikan yang semakin cepat, terbuka, adil, dan merata. ${ }^{17}$ Maka sekolah Islam unggulan haruslah sekolah yang tidak hanya efektif dari berbagai aspeknya, namun ada prestasi atau keunggulan yang ditonjolkan baik nasional maupun internasional.

Disamping itu sekolah Islam unggulah harus mampu mengelola kurikulum yang efektif. Kurikulum adalah perangkat pendidikan yang merupakan jawaban terhadap kebutuhan dan tantangan. ${ }^{18}$ Kurikulum merupakan gagasan pendidikan yang diekspresikan dalam praktik dan juga termasuk seluruh progam pembelajaran yang terencana dari institusi pendidikan. ${ }^{19}$ Maka dari itu sebenarnya inti dari kurikulum itu harus ada tiga pilar yang sedang berlangsung, yaitu adanya transmission of knowledge, processes that seek to facilitate student learning, and product at learning used to acertain wether students have acquired new information.

\section{SIMPULAN}

Semakin banyak perbaikan dan keunggulan sekolah, maka akan semakin meningkatkan posisi tawarannya di masyarakat, termasuk dalam persoalan penerimaan siswa baru. Sekolah yang memiliki berbagai keunggulan akan menumbuhkan kepercayaan masyarakat. Kepercayaan ini bukan takdir melainkan dapat dirintis dan dibangun untuk mewujudkan sekolah unggulan di pedesaan. Sehingga ini menyadarkan

\footnotetext{
${ }^{14}$ Agus Maimun dan Agus Zaenul Fitri, Madrasah Unggulan Lembaga Pendidikan Altrnatif di Era Kompetitif (Malang: UIN Malang Press, 20I0).

${ }^{15}$ Mujamil Qomar, Manajemen Pendidikan Islam (Erlangga, 2008), I89-190.

16 Lawrenze W. Lezotte, What Re-efisioning The Correlates Effekctive School Do, (New York: Intenasional Publising Inc, 1985), 15.

${ }^{17}$ Nur Efendi, Membangun Sekolah Efektif Dan Unggulan, (Tulungagung: IAIN Tulungagung Press, 20I4), 14.

${ }^{18}$ Tim Pengembang MKDP kurikulum dan pembelajaran, Kurikulum dan Pembelajaran, (Jakarta: PT Raja Grafindo Persada, 20I I), 7.

${ }^{19}$ Harsono, Pengantar Problem-Based Learning, (Yogyakarta: Medidka, 2005), 9.
} 


\section{PROCEEDINGS}

\section{ANCOMS 2017}

I $^{\text {st }}$ Annual Conference for Muslim Scholars

Kopertais Wilayah IV Surabaya

kepercayaan masyarakat untuk memburu sekolah unggulan. Tugas utama lembaga pendidikan Islam yang telah meraih kesuksesan di pedesaan adalah menunjukan secara riil kemajuan yang berhasil dicapai kepada msyarakat secara luas, melalui berbagai media publikasi yang dimplementasikan public relations.

Desentralisasi pendidikan Islam merupakan bentuk riil dalam memberdayakan satuan pendidikan atau sekolah sebagai unit layanan utama yang mandiri dan memberdayakan dirinya secara cerdas dan optimum. Desentralisasi pendidikan terjadi jika pemerintah pusat menetapkan keputusan yang secara formal telah dibuat di tingkat pusat dapat dibuat di tingkat lebih bawah yang mengurusi masalah pelayanan pendidikan. Sekolah Islam unggulan adalah sekolah yang efektif dari berbagai aspeknya, ada prestasi atau keunggulan yang ditonjolkan baik nasional maupun internasional. Untuk itu, sekolah unggulan merupakan bagian dari rencana yang ingin dicapai dapat berjalan dengan baik dan tidak ada kesenjangan didalamnya dan mampu diharapkan berhasil dengan baik.

\section{DAFTAR PUSTAKA}

Amstrong, Michael, 2..3. The Art of HRD, Strategic Human Resource Management a Guide in Action Manajemen Sumber Daya Manusia Strategik Panduan Praktis untuk Bertindak, alih bahasa oleh Ati Cahyani. Jakarta: PT Gramedia.

Efendi, Nur. 2014. Membangun Sekolah Efektif dan Unggulan. Tulungagung: IAIN Tulungagung Press.

Harsono. 2005. Pengantar Problem-Based Learning. Yogyakarta: Medika

Iksan. 2009. Manajemen Strategis dalam kompetisi pasar global. Jakarta: Gaung Persada.

Maimun, Agus dan Agus Zaenul Fitri. 2010. Madrasah Unggulan Lembaga Pendidikan Altrnatif Di Era Kompetitif. Malang: UIN Malang Press.

Masrokan, Prim Mutahar. 2014. Manajemen Mutu Sekolah Strategi Peningkatan Mutu Dan Daya Saing Lembaga Pendidikan Islam. Yogyakarta: AR RUZZ Media.

Musa, Otonomi Penyelenggaraan Pendidikan Dasar dan Menengah. Jurnal Pendidikan Vol. 2 No. 2 September 200 I.

Qomar, Mujamil. 2008. Manajemen Pendidikan Islam. Jakarta: Erlangga. 2013. Strategi Pendidikan Islam. Jakarta: Erlangga.

Sagala, Syaiful. 20I I. Manajemen Strategik dalam Peningkatan Mutu Pendidikan. Bandung: Alfabeta.

Setiawan, Purnomo dan zulkieflimansyah. 2005. Buku Seri Manajemen: Manajemen Strstegi. Jakarta: Penerbitan Fakultas Ekonomi Universitas Indonesia.

Syafrudin. 2005. Manajemen Lembaga Pendidikan Islam. Jakarta: Ciputat Press.

Tim Pengembang MKDP Kurikulum dan Pembelajaran. 20II. Kurikulum dan Pembelajaran. Jakarta: PT Raja Grafindo Persada.

Triton. 20I I. Manajemen strategis Terapan Perusahaan dan Bisnis. Jakarta: Oryza. 